RESEARCH ARTICLE

\title{
Keyhole Surgery for Carpal Tunnel Syndrome Using MIS-CTS-Kits (Surgical Technique)
}

\author{
Wongthawat Liawrungrueang $(\mathbb{D})$ and Sunton Wongsiri* $(\mathbb{D}$
}

Department of Orthopaedic Surgery and Physical Medicine, Faculty of Medicine, Prince of Songkla University, Hat Yai, Songkhla 90110, Thailand

*Corresponding author: Sunton Wongsiri, Department of Orthopaedic Surgery and Physical Medicine, Faculty of Medicine, Prince of Songkla University, Hat Yai, Songkhla 90110, Thailand

\begin{abstract}
Background: Carpal tunnel syndrome is the most common hand disease. The standard open technique for carpal tunnel surgery has some wound problems and complications significantly more than minimally invasive surgery. The keyhole technique produces good results with the novel tool of MIS-CTS kits (Minimally invasive surgery for carpal tunnel syndrome kits) was developed to improve effectiveness for surgery.

Method: This is the surgical technique note that the MISCTS kits improve the effectiveness of visualization during surgery and the complete release of the transverse carpal ligament (TCL), and also the safety of using the MIS-CTS kits. The result of this technique shows that the TCL was cut completely. All median nerves could be observed during the operation and were not injured in the previous cadaveric study and clinical study in the author's hospital.

Results: All median nerves could be observed during the operation and were not injured. This technique showed the effectiveness and optional for minimally invasive carpal tunnel surgery.

Conclusions: The study found that the MIS-CTS kits, along with this technique are effective for CTS release in terms of minimally invasive open carpal tunnel surgery.
\end{abstract}

\section{Keywords}

Carpal tunnel syndrome, Minimal invasive surgery, MISCTS-Kits

\section{Introduction}

Carpal tunnel syndrome (CTS) is the entrapment neuropathy of the median nerve. It was found in $3.8 \%$ of the general population [1]. In orthopedic surgery by open carpal tunnel release when conservative treatment fails. Currently, surgery is known to be more effective than conservative treatment [2]. The standard open technique for carpal tunnel surgery has some wound problems and complications significantly more than minimally invasive surgery [3]. The novel tool of ProMIS $^{\circledR}$ (Valor Health Co., Ltd, Bangkok, Thailand) (Figure 1) was developed to improve effectiveness and safety. In this tool with a palmar approach will effectiveness of visualization during surgery and the complete release of the transverse carpal ligament (TCL), and also the safety of using the ProMIS ${ }^{\circledR}$. TCL was cut completely. All median nerves could be observed during the operation and none were injured. Previous author studies have shown that all twenty patients were successful surgery in the author's technique, hence the name Wongsiri Technique. Carpal tunnel surgery took 6.8 minutes operative time and had a $12 \mathrm{~mm}$ incision. One patient experienced pillar pain which was cured in one month. After surgery, patients can return to work in one week (average 7.3 days). The author's technique demonstrated good outcomes similar to the endoscope. By contrast with the endoscopic surgery, the author's technique with the ProMIS ${ }^{\circledR}$ reduced pre-op, operating and post-op time, many resources, and significant costs and resulted in no nerve problems or complications [4]. This technique showed effectiveness and safety for minimally invasive carpal tunnel surgery so that it was routine surgery in the author's hospital for used this technique since 2015.

\section{Methods}

\section{Indications and contraindications}

ProMIS $^{\circledR}$ is a surgical instrument used for the treatment of carpal tunnel syndrome for the failure of con-

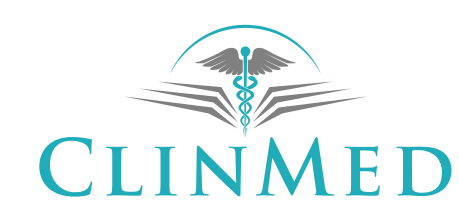

INTERNATIONAL LIBRARY

Citation: Liawrungrueang W, Wongsiri S (2020) Keyhole Surgery for Carpal Tunnel Syndrome Using MIS-CTS-Kits (Surgical Technique). Int Arch Orthop Surg 3:018. doi.org/10.23937/2643-4016/1710018 Accepted: April 13, 2020; Published: April 15, 2020

Copyright: (C) 2020 Liawrungrueang W, et al. This is an open-access article distributed under the terms of the Creative Commons Attribution License, which permits unrestricted use, distribution, and reproduction in any medium, provided the original author and source are credited. 


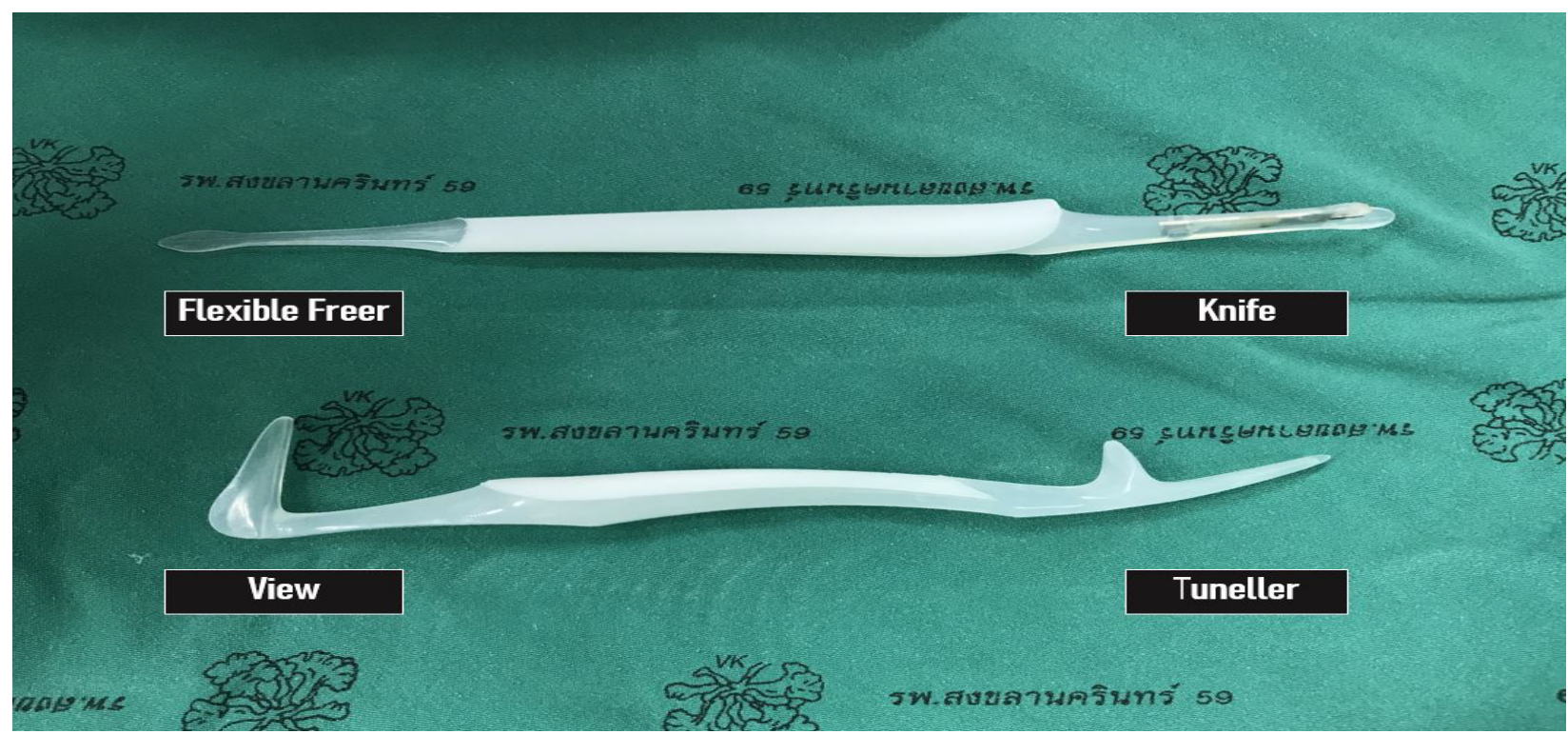

Figure 1: The novel tool of ProMIS $®$.

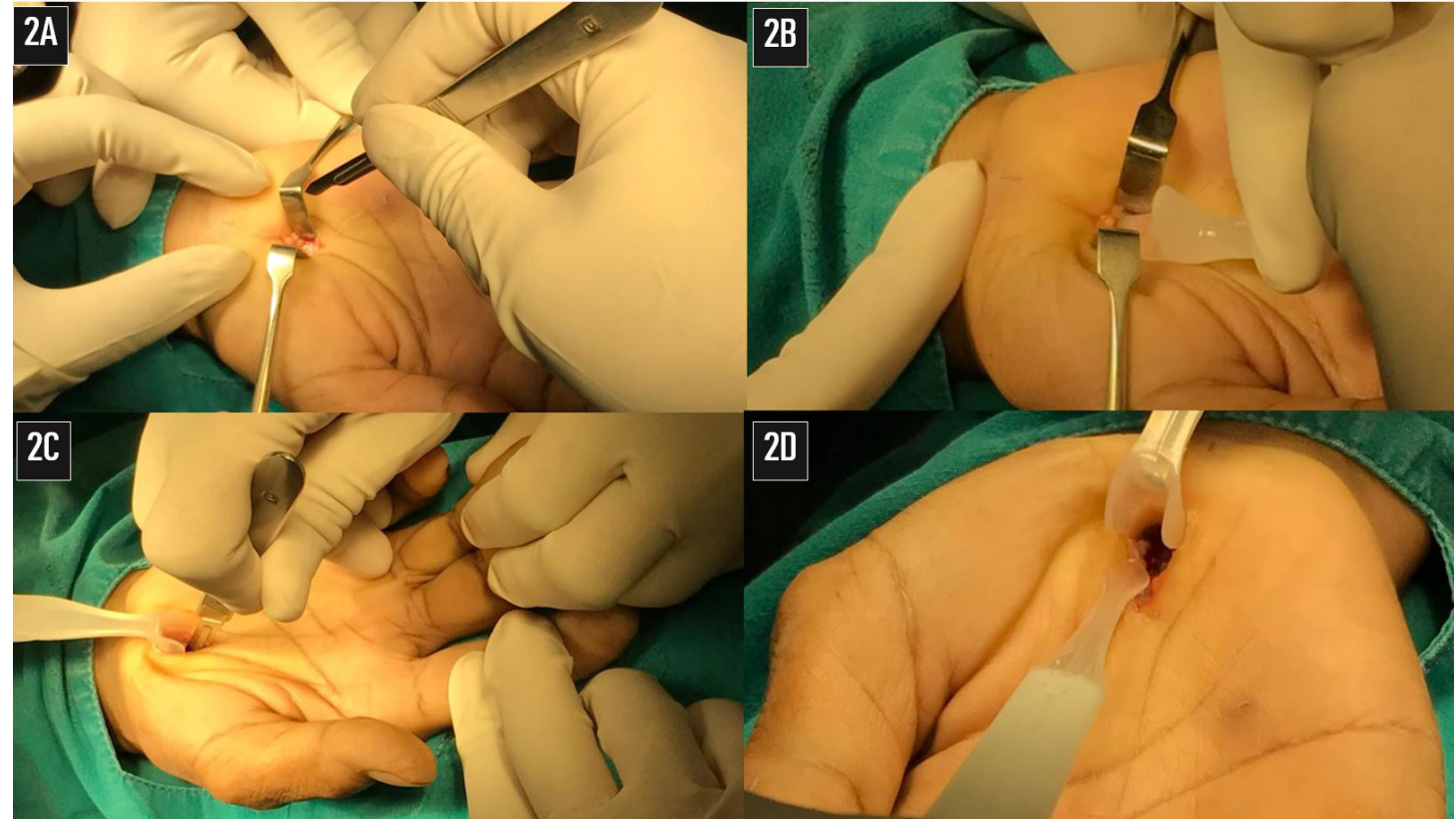

Figure 2: The surgical technique in minimally invasive technique with small incision using ProMIS $₫$

servative treatment for 6 to 12 weeks of night neutral wrist splint, substantial symptoms (thenar weakness, atrophy, or two-point discrimination changes), prolonged symptoms more than 6 months with or without trial of conservative treatment and patient prefer minimally invasive surgery using ProMIS ${ }^{\circledR}$.

Contraindication include infection in the area of the carpal tunnel, acute infection of the hand, tissue adhesion in the carpal tunnel area which may potentially compromise the safe and precise separation of the carpal ligament, previous soft tissue injury in the area of surgery and congenital deformity of the wrist.

\section{Surgical anatomy}

The anatomy carpal tunnel forms an arch by four bony prominences (pisiform, tubercle of the scaphoid, hook of hamate and tubercle of trapezium). The transverse carpal ligament or flexor retinaculum is continuous in the carpal tunnel. Superficially the palmaris longus tendon passes anterior to the flexor retinaculum to become continuous with the palmar fascia. Deep to the palmar fascia, a thick ligamentous band forms the superficial border of the carpal tunnel, also referred to as the transverse carpal ligament. The flexor retinaculum and the transverse carpal ligament are considered by some author synonymous terms [5-7].

\section{Surgical technique}

The surgical technique in minimally invasive technique with small incision using ProMIS $^{\circledR}$. (Available on youtube at https://youtu.be/IOIYjmkIEMw) 
1. The incision direction is the line between the middle finger and ring finger along to the wrist crease. Incision $15-18 \mathrm{~mm}$, start away from the wrist crease about 2 to $2.5 \mathrm{~cm}$ distally.

2. The palmaris longus tendon is retracted by Senn retractors, then the $T C L$ is observed at the base (Figure 2A).

3. Scissors are used to create working space underneath the palmaris longus tendon and palmar aponeurosis.

4. The navigator was inserted to increase the size of the space for visual enhancer insertion (Figure 2B).

5. The visual enhancer is inserted in the space beneath the palmaris longus tendon and palmar aponeurosis. The transverse fiber of the TCL is observed from the bottom view. The visual enhancer improves the visual field by shielding the soft tissue around the operative field.

6. The TCL is cut by scalpel longitudinally at the top to create the long groove for the cutting guide and reducing the over the prominence of TCL. The TCL is cut at the distal part for opening entry; then a flexible freer is used to detach the fibrous tissue from the median nerve and the TCL (Figure $2 \mathrm{C}$ and Figure 2D).

7. The TCL cutting blade is pushed straight to cut the TCL from the distal to proximal along the groove until antebrachial fascia that is 2 to 2.5 $\mathrm{cm}$ proximal to the wrist crease. Finally, complete release can be directly checked by direct vision via the visual enhancer or through the use of a probe with the ProMIS ${ }^{\circledR}$, the TCL can be seen clearly through the small incision (Figure $3 \mathrm{~A}$, Figure $3 \mathrm{~B}$ and Figure $3 \mathrm{C}$ ).

8. The wound is irrigated with normal saline and the skin was closed with vertical mattress suture using Nylon 3-0 (Figure 3D).

9. Elastic bandage was applied for compression and immobilization.

\section{Post-operative management}

Because of a minimally invasive procedure, post-operative care is simplified. After three days, the patients were allowed to use such as light-duty work. Most patients were allowed to return to work normally after two weeks. The patients were allowed to work hard, lift heavy objects and play sports after a month if there were no pain. In two to four weeks after the surgery, massaging of the scar area with a topical steroid, lotion or scar remover helps soften the scar and reduce the pain.

\section{Results}

The author's preliminary study found that all carpal tunnel operations were successful. Demographic data have shown that there were nine women and one male (age range: 49-62 years). Most clinical signs and symptoms are numbness, positive Tinel signs, positive Modified-Phalen test, and positive Durkan compression test. The average wound size is $13 \mathrm{~mm}$. (range: 12-15 $\mathrm{mm}$.) After 3 months, the surgical scar has reduced to $8 \mathrm{~mm}$. (range: 7-9 mm.) In a minor complication, one patient had pillar pain without scar pain. After using the topical steroids three times a day, the pillar pain was cured in one month. Patients were able to work in 7 days (range: 5-9 days) and return to heavy lifting

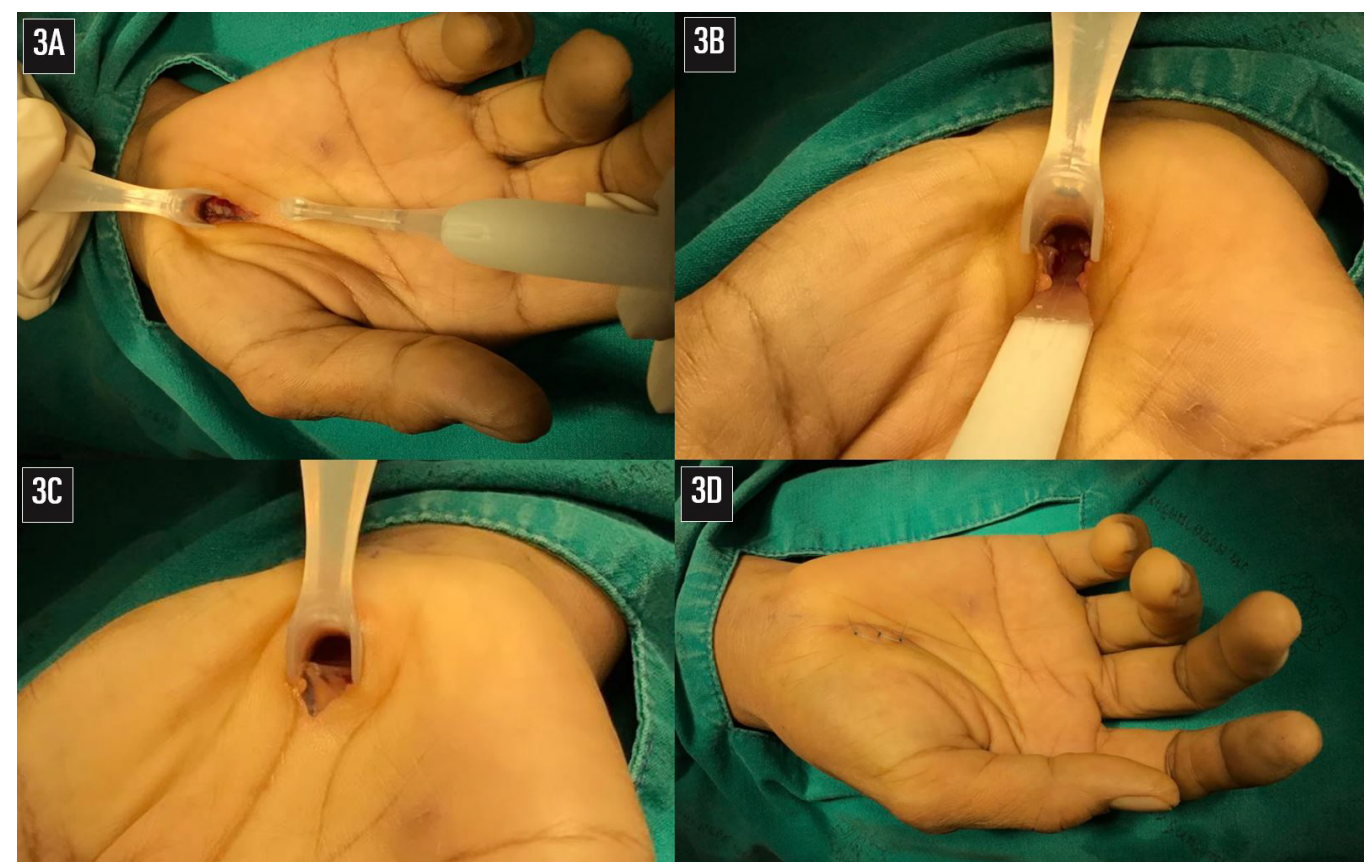

Figure 3: TCL can be seen clearly through the small incision. 
on average 28 days (range: $20-30$ days). All median nerves could be observed during surgery and were not injured. This technique [8-10] demonstrated effectiveness and was a good option for minimally invasive carpal tunnel surgery $[11,12]$.

\section{Discussion}

Key success factors of carpal tunnel surgery are clear visualization and complete release. Specific techniques and specific equipment are improving visualization and TCL cutting. The visual enhancer and knife are easy to approach to target with specific designs for CTS that avoid critical structural damage. The minimally invasive with a mini-incision of 15 $\mathrm{mm}$ can reduce soft tissue trauma, reduce pain fast healing and fast recovery [11]. Warnings and precautions about ProMIS ${ }^{\circledR}$ that reuse the ProMIS $^{\circledR}$ may cause a breakage of the device and possibly injure the patient. A high level of surgical skill and qualified training specific to ProMIS ${ }^{\circledR}$ is required. The navigator tip of ProMIS $^{\circledR}$ is to be used to create a space just above the transverse carpal ligament. Insertion in the wrong direction or incorrect usage may cause an injury to proximate cutaneous nerves or other tissue. The ProMIS ${ }^{\circledR}$ Knife may cause an injury to a median nerve if used in a wrong direction or wrong technique and/or if it has fibrous tissue adhering to the median nerve. The median nerve should be completely free from fibrous tissue and all caution must be taken to prevent any injury. Tissue irritation may occur if the patient has an immune response or allergic reaction against the polypropylene. In the case of this rare occurrence, please see an appropriate doctor. Minimally invasive surgery for carpal tunnel release is a specialized technique and tool that was developed for CTS. With the correct landmark and anatomy understanding, it can prevent injuries to the median nerve, recurrent branches of median nerves and superficial palmar arch. There are fewer problems of wound, such as wound inflammation, infection and painful scar. Small surgical wounds are less likely to occur than conventional surgery [12].

\section{Conclusions}

The novel tool of ProMIS ${ }^{\circledR}$ (Valor Health Co., Ltd, Bangkok, Thailand) was developed to improve effectiveness. This tool will improve the effectiveness of visualization during surgery and the complete release of the transverse carpal ligament (TCL), and also the effectiveness of using the ProMIS $^{\circledR}$. The result of this tech- nique shows that the TCL was cut completely. All median nerves could be observed during the operation and were not injured. This technique showed the effectiveness and optional for minimally invasive carpal tunnel surgery.

\section{Acknowledgments}

I give all credit to Prince of Songkla University (PSU). PSU is a surgical knowledge resource that allows me to undergo to learn surgery to help patients. PSU provides significant opportunities and funds for the development of innovative CTS surgical devices. Sometimes I and my medical team use the name PSU retractor or Mini \& SURE as CTS surgical devices to honor the PSU, although the official name of this device is ProMIS $^{\circledR}$.

\section{References}

1. Atroshi I, Gummesson C, Johnsson R, Ornstein E, Ranstam J, et al. (1999) Prevalence of carpal tunnel syndrome in a general population. JAMA 282: 153-158.

2. Gerritsen AA, de Vet HC, Scholten RJ, Bertelsmann FW, de Krom MC, et al. (2002) Splinting vs surgery in the treatment of carpal tunnel syndrome: A randomized controlled trial. JAMA 288: 1245-1251.

3. Uchiyama S, Itsubo $T$, Nakamura $K$, Kato $H$, Yasutomi $T$, et al. (2010) Current concepts of carpal tunnel syndrome: Pathophysiology, treatment, and evaluation. J Orthop Sci 15: 1-13.

4. Wongsiri S (2015) Keyhole surgery of CTS using novel tool MiniSure. BMC Proc 9: 79.

5. Gray H, Clemente CD (1985) Anatomy of the human body. (13 ${ }^{\text {th }}$ edn), Lippincott, Philadelphia, 531.

6. Spinner M (1984) Kaplan's functional and surgical anatomy of the hand. ( $3^{\text {rd }}$ edn), Lippincott, Philadelphia, 261-263.

7. Hoppenfeld S, deBoer P (1984) Surgical exposures in orthopaedics: The anatomic approach. Lippincott, Philadelphia, 162-165.

8. Wongsiri S, Suwanno P, Tangtrakulwanich B, Yuenyongviwat V, Wongsiri E (2008) A new tool for mini-open carpal tunnel release - The PSU retractor. BMC Musculoskelet Disord BioMed Central 9: 126.

9. Wongsiri S (2013) The new wave of Carpal Tunnel Syndrome (CTS) surgery. Bangkok Med J 6: 80-85.

10. Wongsiri S (2015) Keyhole surgery of CTS using novel tool MiniSure. BMC Proceeding 2015 9(Suppl 3): A79.

11. Wongsiri S, Liawrungrueang W (2020) Minimally Invasive Carpal Tunnel Release (CTR) Using the Wongsiri Technique with MiniSURE. Adv Orthop 2020: 6273723.

12. Liawrungrueang W, Wongsiri S (2020) Effectiveness of Surgical Treatment in Carpal Tunnel Syndrome Mini-Incision Using MIS-CTS Kits: A Cadaveric Study. Adv Orthop 2020: 8278054 .

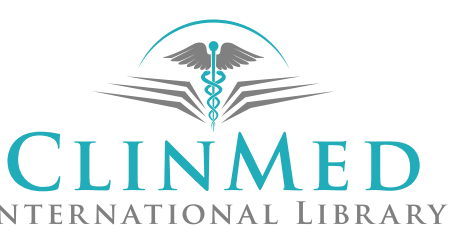

